\title{
ANTROPÔNIMOS NA LÍNGUA TURCA: A DINÂMICA NA ESCOLHA DE PRENOMES E SOBRENOMES NA TURQUIA PÓS-REPÚBLICA
}

Marco Syrayama de Pinto ${ }^{1}$

Abstract: This paper aims at examining the changes in naming processes brought about by the advent of the republic in Turkey in 1923, which has seen drastic changes in several aspects of social, cultural and linguistic spheres. Along with the creation of a policy of purification of the language from foreign influences, which was part of a series of reforms promulgated by Atatürk to bring the country closer to the West, the Soyadı Kanunu (1934-6) "Surname Law" was enacted, which had a great impact on the choice of given names and surnames. From an inventory of mostly Arabic names, which by no means have ceased to exist, there came an increase in the choice of words of Turkish stock.

KeYwords: Antroponimia, Turkish language, Arabic language.

\section{Introdução}

A onomástica (do grego ôvouạ "nome”), ou o estudo científico da etimologia dos nomes próprios, pode ser estudada sob vários ẩngulos e é disciplina auxiliar à linguística, filologia, psicologia, sociologia, antropologia, dentre outras. A onomástica, por seu turno, é subdividida em duas outras ciências, a antroponímia e a toponímia, recaindo o enfoque da primeira (do grego

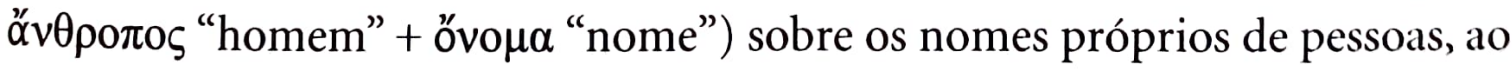

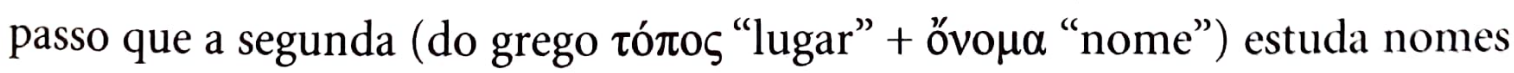

I Mestre em Língua e Literatura árabe, FFLCH/USP, e atualmente doutorando em Filologia e Língua Portuguesa na mesma instituição. 
geográficos. Tal divisão, contudo, transparece sua arbitrariedade pelo fato de haver por vezes intercâmbio entre as duas ciências, pois há topônimos que são baseados em antropônimos, como em Washington, de George Washington, sendo o oposto também verdadeiro: Israel também é usado como antropônimo (CRYSTAL, 1997, p. 112).

\subsection{As tendências antroponímicas no turco}

A análise antroponímica pode revelar aspectos linguísticos relevantes, visto que as tendências também provocam mudanças linguísticas, das quais uma é o empréstimo linguístico. $\mathrm{O}$ inventário de nomes próprios também pode mudar com o tempo, refletindo a própria dinâmica das sociedades. No caso do turco, ele demonstra as mudanças drásticas sofridas pela sociedade desde a adoção em massa do Islã no século XI até o advento de uma república laica em 1923, assim como a reforma linguística que teve início na década de 30, a partir dos quais se podem observar mudanças significativas na escolha de nomes próprios. Assim, pode-se dividir o inventário antroponímico turco e suas práticas nomeadoras em três fases distintas: a fase que antecede a aceitação do Islã, a fase após a conversão ao Islã e a fase pós-república, ou contemporânea. A segunda fase é particularmente especial no sentido de que foi a que maior influência exerceu tanto nos rituais nomeadores quanto na quantidade de nomes dados, muito embora os turcos tenham abraçado outras religiões antes dessa, como o xamanismo, o maniqueísmo e o budismo. Obviamente, seu segundo interesse reside no fato de que o principal veículo propagador de nomes após a conversão dos turcos ao Islã tenha sido o árabe, seguido do persa. Segundo İnan, a adoção de nomes árabes pelos turcos data do início do século VIII, período esse ainda incipiente da religião islâmica. Contudo, seu uso ficou restrito somente a membros da aristocracia turca (INAN, 1958, p. 492 apud DUMAN, 2004, p. 157). A camada mais antiga de nomes árabes data dessa época. Durante o Império Otomano, o sistema prevalente de nomeação era essencialmente baseado nos costumes árabes, segundo os quais se dava um oll dois nomes próprios seguidos de uma alcunha. Tal alcunha podia se referir a um apelido, lugar de origem, ocupação ou algum traço físico característico, como no nome Ankaralı Ali zade Hasan, que remetia a Hasan filho de Ali da 
cidade de Ancara (zade, de uma palavra persa, zāde, que significa "filho"), ou Topal Mehmet, que se referia a Mehmet, o manco (topal) e ayakkabıcı İbrahim ao sapateiro (ayakkabıci) Ibrahim. Dá-se também um segundo nome próprio, não oficial, que é denominado göbekadı (lit. "nome umbilical"), pois é durante o processo de parto que tal nome é concedido, geralmente na presença de um homem como o pai ou o avô, que o pronuncia formalmente. Esse nome geralmente relacionado com o Alcorão, personagens da tradição sunita, os primeiros califas ou companheiros do Profeta, tais como Mehmet, Osman, Hasan, Ali, İbrahim, ou mesmo nomes de origem turca, como Orhan, pertencente à história da dinastia otomana.

\subsection{A Lei do Sobrenome (Soyadı Kanunu) de 1934 e 1936}

Como uma das reformas - dentre várias igualmente polêmicas, tais como a mudança do alfabeto, a purificação da língua de elementos exógenos e a completa separação religião/Estado - adotadas por Atatürk para a ocidentalização da nova Turquia republicana, foi sancionada uma lei em 21 de junho de 1934, a Lei do Sobrenome (ou (Soyadı Kanunu, em turco), que entraria em vigor em $1^{\circ}$. de janeiro de 1935, a qual rezava que os sobrenomes deveriam ser obrigatoriamente adotados, pois até então seu uso era opcional. Essa lei também estipulou que os prenomes fossem preferivelmente de origem turca. Contudo, embora tal prática tenha sido adotada por alguns grupos urbanos e serventes civis, a maioria da população não parecia disposta a mudar um costume que séculos de uso haviam consagrado. Devido à confusão causada pela falta de compreensão da criação dessa lei, que, apesar de ter como princípio imitar a sociedade europeia da época, também pretendia facilitar a tributação e o recrutamento ao serviço militar (obrigatório a todos os homens até os dias de hoje, sob pena de aprisionamento, em caso de não comparecimento), a lei para o registro de nomes somente passou a ter efeito a partir de uma prorrogação, que se deu em janeiro de 1936.

\subsection{Origens dos nomes na Turquia ao longo dos tempos}

De acordo com investigações sobre os padrões de nomeação de muçulmanos na época medieval, foi constatado que certos nomes árabes foram utilizados 
por um longo período de tempo, três dos quais ainda são extremamente comuns na Turquia secular moderna, a saber: Mehmet (< ár. muhammad²), Ahmet (< ár. ahmad) e Ali (< ár. ${ }^{c} a l \bar{l}$ ) (BULLIET, 1978, p. 489). A fim de verificar os padrões mutantes (ou não), Bulliet se baseou na lista de nomes de todos os membros do parlamento turco entre os anos 1920 e 1973.

Um outro, estudo realizado pela linguista turca Derya Duman num artigo sobre a caracterização do inventário dos nomes próprios no turco, estabelece uma sistematização dos antropônimos dessa língua através da investigação da influência das outras línguas via empréstimo linguístico no inventário de nomes na Turquia. A sistematização foi feita de acordo com uma divisão dos períodos históricos desde o início do século XX, como pode ser observado na tabela abaixo (DUMAN, 2004, p. 155-77):

Distribuição dos nomes ao longo de períodos históricos de acordo com a origem $(\%)^{3}$

\begin{tabular}{|l|c|c|c|c|c|c|c|c|c|c|}
\hline \multirow{2}{*}{ Origem } & Pré- & $1901-$ & $1921-$ & $1931-$ & $1941-$ & $1951-$ & $1961-$ & $1971-$ & $1981-$ & $1991-$ \\
& 1900 & 1920 & 1930 & 1940 & 1950 & 1960 & 1970 & 1980 & 1990 & 1999 \\
\hline Árabe & 85,7 & 82,1 & 85,8 & 70,5 & 63,5 & 66,4 & 60,8 & 48,4 & 34,2 & 55 \\
\hline Hebraico & 7,1 & 6,9 & 5,6 & 5 & 4,7 & 6,3 & 5 & 2,38 & 5,7 & 5 \\
\hline Persa & 2,36 & 2 & 0,9 & 3,36 & 10,8 & 9,8 & 6,52 & 15 & 11.4 & 10 \\
\hline Turco & 2,9 & 6,9 & 5,6 & 16,8 & 14,1 & 12,1 & 20,2 & 23,8 & 32,8 & 20 \\
\hline $\begin{array}{l}\text { Turco e } \\
\text { Árabe }\end{array}$ & & 0,4 & & 1,68 & 2 & 2,89 & & 1,58 & 4,2 & \\
\hline
\end{tabular}

(continua)

2 Atualmente, Melımet é reservado apenas a nomes pessoais comuns, sendo que o Profeta fundador do Islã é referido por Muhammed, ao passo que a terceira variante Mehemmed é usada para se referir a sultões otomanos. Note-se a mudança fonética do original ár. em Mehmet, com a simplificação das geminadas $/ \mathrm{m} /$, bastante comum em se tratando da reprodução dos empréstimos árabes no turco, a harmonia vocálica em direção a /e/, tanto na primeira quanto na terceira forma, além do ensurdecimento do $/ \mathrm{d} / \rightarrow / \mathrm{t} /$, que são mudanças comuns na língua turca (Cf. LEWIS, 1967, p. 6).

Adaptado da tabela de DUMAN, 2004, p. 164. 
(contimuagias)

\begin{tabular}{|l|c|c|c|c|c|c|c|c|c|c|}
\hline Origem & $\begin{array}{c}\text { Pré- } \\
1900\end{array}$ & $1901-1921-$ & $1931-$ & $1941-$ & $1951-$ & $1961-$ & $1971-$ & $1981-$ & $1991-$ \\
\hline $\begin{array}{l}\text { Turco e } \\
\text { Persa }\end{array}$ & 1,18 & 0,4 & 0,9 & 1,68 & 2 & 1,7 & 4,3 & 3,9 & 5,7 & \\
\hline $\begin{array}{l}\text { Árabe e } \\
\text { Persa }\end{array}$ & & 0,4 & & 0,8 & 0,67 & 0,57 & & 0,79 & 1,4 & \\
\hline \begin{tabular}{l} 
Outras \\
\hline
\end{tabular} & & 0,4 & & & & & 1,4 & 3,1 & 4,28 & 10 \\
\hline
\end{tabular}

De um banco de dados que totalizou 1.178 nomes, os nomes mais comuns na Turquia moderna, segundo esse estudo, são: Mehmet, Fatma, Ahmet, Ali, Ayşe, Emine, Hatice e Mustafa, o que corrobora os achados de Bulliet, que observou a alta frequência de três dos nomes dessa lista. O que pode ser deduzido desses números é a influência ainda ativa da língua árabe nesta determinada área dos nomes próprios através da religião islâmica, que é a predominante no país. Obviamente tais práticas obedecem a tendências político-sociais vigentes nas diferentes épocas, visto que a tomada do poder de partidos com inclinações religiosas $^{4}$ (nas décadas de 50 e 90, ver tabela) coincidiu com o aumento no número de nomes de origem árabe, especialmente relacionados com o Islã.

Deve-se frisar a importância que tal prática tem na vida das pessoas em geral, visto que elas carregarão um designativo apenas ${ }^{5}$ pelo resto de suas vidas,

4 Nas eleições de 1950, o Partido Democrata (Demokrat Parti), liderado por Adnan Menderes, derrotou o até então partido vigente fundado por Atatürk, o Partido Popular Republicano (Cumhuriyet Halk Firkasi), ficando no poder por dez anos. Aquele foi caracterizado por sua política liberal no tocante a assuntos religiosos, uma das principais causas de sua vitória, pois o povo turco ansiava ver o Islã restaurado em seu lugar prévio na Turquia (LEWIS, 1955, p. 131). A título de curiosidade, uma das primeiras medidas tomadas pelo novo governo democrata foi a reinstauração do árabe na chamada à prece, o ezan, que antes era feita em turco. Na década de 90 , um outro partido islamista, o Partido da Prosperidade (Refah Partisi), subiu ao poder com 21\% dos votos em 1995 , sob a liderança de Necmettin Erbakan. Entre outras medidas, ele estreitou laços com outros países islâmicos linha-dura, como o Irã e a Líbia. O partido foi abolido em 1997, após golpe militar.

5 Há exceçōes, como no caso de algumas tribos da Austrália e Nova Zelândia, cujos membros possuem dois nomes, um nome "público", para uso geral, e outro nome "secreto", que somente Deus e os membros da família conhecem. O tabu também é responsável pela troca de nomes, como na 
o que acarreta uma cuidadosa cogitação a que os pais se devotam na hora de nomear seus filhos, em para qualquer sociedade. Essa prática, que em algumas sociedades se transforma em um verdadeiro ritual, segue algumas tendências observáveis, como a adoção de um nome de uma personalidade histórica ou literária, viva ou não; nomes de animais, lugares, presságios, ou nomes ligados a qualidade louvável ou mesmo indesejável em um indivíduo ${ }^{6}$ ou a circunstâncias marcantes observadas pelos pais no momento da nomeação, sem mencionar o aspecto religioso, que tem uma grande influência nesse costume social. Note-se também que a mudança linguística, operante em todos os níveis da língua, tampouco poupa os antropônimos, visto que eles podem perder sua transparência semântica com passar do tempo, não sendo prontamente compreendidos pelos falantes, pelo fato de serem empréstimos de uma língua.

\subsection{Antropônimos de origem árabe correntes na Turquia moderna}

Abaixo segue uma classificação por categoria semântica dos antropônimos em uso corrente na Turquia moderna oriundos da língua árabe:

a) relacionados com a religião islâmica, baseados em figuras famosas da época do início do Islã, constituindo a camada mais antiga de empréstimos do árabe na categoria: Bilâl (< bilāl), Emin (<'amīn), Muhammedl Mehmet, Faruk (<farūq), Ahmet, Hüseyin (< husayn), Hasan (< hasan); dos quatro califas Abu Bekir (<'abū bakr), Osman (<'utmān), Ömer (<'umar) e Ali $\left(<^{c}\right.$ ali $)$;

b) baseados nos 99 nomes de Alá:? Ekber "O Maior" (< ár. 'akbar), Aziz "O Prezado" (< ár. 'azìz), Kadir "O Todo-poderoso" (< ár. qādir), Sami "O que (tudo) ouve" (< ár samīc);

cultura polinésia. Na ocasião da morte de alguém com um determinado nome, os outros membros da comunidade com o mesmo nome terão que adotar outro no lugar dele (Cf. CRYSTAL, 1997, p. 9).

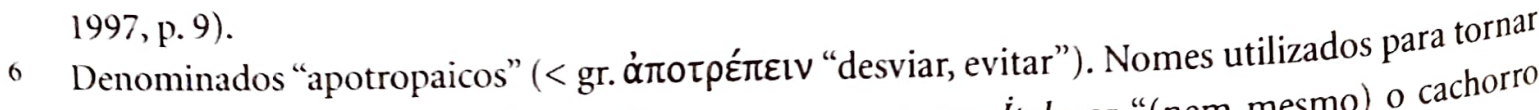
a criança indesejável a espíritos malignos, como no turco Italmaz "(nem mesmo) o cachorro pega", Coçkabay "o homem porco" e Kabanbay "javali" (Cf. DUMAN, 2004, p. 157.)

7 Denominados em árabe al'asmä' alhusnà, lit. "os nomes mais bonitos". 
c) retirados de suras do Alcorão: Kamer"lua" (< ár. qamar), Nisa "mulheres" (< ár. nis $\bar{a}^{\prime}$ );

d) meses do calendário islâmico: Ramazan (< ár. ramaḍān), Şaban (< ár. ša bān), Muharrem (< ár. muharram), Recep (< ár. rajab), Safer (< ár. șafar), Şevval (< ár. šawwāl); ${ }^{8}$

e) festividades islâmicas: Kurban "sacrifício" (< ár. qurbān), Bayram "festividade"; 9

f) palavras que expressam qualidades louváveis: Iffet "castidade" (< ár. “iffa ${ }^{t}$ ), Ísmet "virtude" (< ár. “iṣmat), Sadık "honesto" (< ár. șādiq);

g) nomes escolhidos abrindo-se a esmo uma página do Alcorão, cujos significados são negativos: Kezban (também sob a forma Keziban) "mentirosamente" (< ár. kadiban), Nafiz "penetrante" (< ár. nāfid ), Nazile "desastre" (< ár. nāzilat);

h) nomes islâmicos, adotados após a década de 40: Hale "auréola" (< ár.

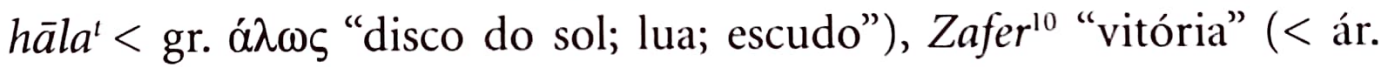
dafar);

8 Digno de observação é que com uma única exceção, Sevval, o restante dos nomes é masculino. A razão, porém, nos parece um tanto obscura. Quanto ao resto dos meses islâmicos não listados acima, que são mais seis, curiosamente não foram adotados como nomes próprios, talvez pelo fato de serem todos nomes compostos, o que faria deles cacofônicos aos ouvidos dos falantes:

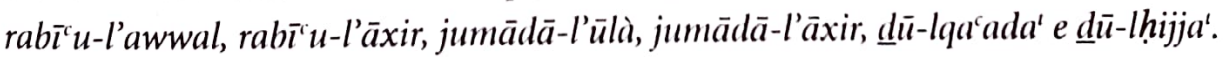

9 A "Festa do Sacrifício" islâmica, conhecida como "îdu-l-adhì em árabe, que por sua vez foi decalcada como Kurban Bayramı no turco. Bayram é uma palavra antiga no léxico turco, que entrou sob a forma badram, datada do século XI, sendo provavelmente um empréstimo de uma língua do ramo iraniano (Cf. TIETZE, 2002, p. 297 e NIŞANYAN, 2003, p. 44). Curioso também notar, dada sua importância no contexto religioso islâmico, que tal palavra não fora suplantada pela equivalente árabe ${ }^{i} \bar{d}$, que nem mesmo fora adotada pelo turco. Seu uso, contudo, não é exclusivamente religioso, cf. Çocuk Bayramı "Dia das Crianças" e o Dil Bayramı "Dia Nacional da Língua Turca", ambos instituídos por Atatürk.

Seu sinônimo, başarı, um neologismo criado em 1935, é mais comum na língua cotidiana. Além desse, a Academia Turca de Letras pretendia, e o fez com bastante êxito, substituir um outro sinônimo de origem árabe muvaffakiyet (<ár. muwaffaq + suf. -yat) que é, inclusive, uma inovação da língua turca, pois a palavra "sucesso" é expressa em ár. pela palavra tawfíq, oriunda, contudo, da mesma raiz $w-f-q$. A inspiração para a criação desse vocábulo foi a secularização da Turquia, pois 
i) nomes sem conotações religiosas, baseados em palavras de uso cotidiano, dos mais diversos campos semânticos: Mercan "coral" (< ár. marjān ou murjān), Elveda "adeus" (< ár. alwad $\bar{a}^{c}$ )," Şöhret "fama" (< ár. šuhrat), Leyla"noite" (< ár laylà).

Contudo, percebe-se que a influência antroponímica foi produtiva no sentido de que, embora não exista gênero propriamente dito na língua turca, ele existe no árabe, que emprestou especialmente um sufixo que transforma palavras masculinas em femininas, ár. -(i)(y) $\mathrm{a}^{\mathrm{t}}>$ turco (i)(y)e, o que possibilitou a formação de outras palavras:

- Habip “amado" (< ár. habīb) $\rightarrow$ Habibe “amada”.

- Emin “(o) confiável” (ár. < 'amīn) $\rightarrow$ Emine “(a) confiável”.

- Zeki“(o) inteligente” (ár. $\underline{d} a k \bar{\imath}) \rightarrow$ Zekiye “(a) inteligente”.

No entanto, nem todos os nomes femininos que levam tal sufixo necessariamente têm um homólogo masculino, como o nome Hediye (com variante Ídiye) "presente, regalo" (< ár. hadiyyat). ${ }^{12}$

A distinção de gêneros de nomes turcos de origem árabe pode ser resumida fonologicamente da seguinte forma: os que terminam em /i/ ou /y/ são masculinos, como Ali (<' $a l \bar{l})$, Şükrü (<šukr), Hilmi, Nudi, Naci, ao passo que os femininos, sem mencionar o já visto acima (i)(y)e, terminam em /āal, como em Elveda, Leyla. A existência desses dois fonemas para distinguir os nomes

os ideais de ajuda divina do empréstimo já não estavam mais em voga. Outras palavras de cunho religioso que foram substituídas na linguagem popular foi o derivado desse empréstimo árabe, muzaffer "vitorioso" (< ár. mudaffar "id."), e mansur "auxiliado por Deus" (<ár. manșūr “id."), sendo trocadas pelos neologismos başarıl, derivado do já aludido acima başarı, e yener (< v. yenmek "conquistar"), que inclusive se tornou também um antropônimo masculino ou feminino (Cf. HEYD, 1954, p. 94).

11 Esta palavra, que é usada para nomes femininos, é curiosa no sentido de que é o único antropônimo cuja origem é uma interjeição. Ela é utilizada no turco, mas limitada a contextos poéticos.

Note-se que hadiyya', no árabe, foge à regra de outros substantivos femininos inanimados comuns, pois possui um plural irregular, hadāyā, sendo que os plurais regulares são formados através da adição do sufixo -āt, como em kalima' $\rightarrow$ kalimāt. 
femininos pode ser explicada pelo fato de que cada um deles representa um fonema distinto da palavra original árabe: $/ \mathrm{a} />\mid \varepsilon /$ e $/ \bar{a} />/ \bar{a} /$, distinção essa preservada rigorosamente também nos empréstimos árabes pertencentes ao léxico comum, não antroponímico. Há, contudo, algumas exceções, como os nomes masculinos Mustafa (< ár. muștafà "eleito, escolhido"), Rıza "consentimento; escolha" (< ár. riḍ̄ [']), Ziya "luz, claridade" (< ár. diy $\bar{a}$ '), que, embora terminados em /ā/, não são femininos; e o feminino Zeyni "ornamental, decorativo" (< ár. zaynī), que, apesar de terminar em $/ \overline{1} /$, não é masculino. Note-se também uma atribuição de gênero no turco simplesmente pela ocorrência dos fonemas femininos /a/, /â/ ou /e/, sem que essas palavras tenham alguma conotação feminina no original árabe:

- Esra "mais rápido" < ár. 'asra comparativo do adj. sarīc "rápido", que existe sob a forma turca seri, ${ }^{13}$ embora essa seja de uso infrequente.

- Serra "abundância" < ár tarāa.14

Note-se, também, que tal sufixo foi se acomodando na língua turca, que o usou até mesmo afixado a antropônimos de origem turca ou persa, não se restringindo a antropônimos árabes somente:

- Dursune "que ele/ela fique", composto do verbo turco durmak "parar, ficar" no modo subjuntivo $+-e<$ ár. $-a^{t}$.

13 O turco emprega o advérbio invariável daha "mais" para formar o comparativo de adjetivos, que sempre os precede: daha seri (ou mais comumente çabuk, ou hızlı) "mais rápido".

14 Caso insólito da ocorrência da geminada / rr/ nesta palavra turca, sendo que no original árabe nīo há. A tendência, aliás, é inversa, ou seja, de o turco simplificar as geminadas dos empréstimos: hamal "carregador" < ár. ḥammāl "id.", kasap "açougue; açougueiro" < ár. qașșāb "açougueiro", saraç "coureiro" < ár. sarrāj "seleiro", < hamam "banho turco" < ár. hammām "fonte termal". Isso também ocorre com a vibrante $/ \mathrm{r} /$, como na palavra kere "vez, turno" < ár. karril. Pelo fato de serra nâo ser usada no léxico ativo do turco (somente como nome próprio), niáo consta dos dicionários etimológicos dessa língua. Porém, se pensarmos que há uma palavria sera, com variante ser (provavelmente < francês serre, com o mesmo sentido), que supostamente seria a forma pela qual entraria na língua turca, e que significa "estufa", é provável que o / $/$ adicional tenha sido acrescentado propositalmente para diferenciar dessa última. Cf., porém, kare "quadrado" < francês carré "id.". 
- Sahine: composto de şahin "falcão" $(<$ persa šăhīn $)+-e<$ ár. $-a^{t}$.

- Serviye: servi "cipreste" (< persa sarv) + -ye< ár. -iyat. ${ }^{15}$

Nomes híbridos são também bastante comuns, mas em cada caso a mistura se dá entre duas línguas apenas:

- árabe e persa: Ayşegül (ár. 'ā'išat + persa gol "rosa”), Güleser (persa gol + ár. 'atar "efeito; impressão; ruína antiga").

- árabe e turco: Aynur (turco ay "mês" + ár. nūr "luz"), Nurdan (ár. nūr + turco - $d A n$ “de (indicando origem)", İknur (turco ilk “primeiro(a)" + ár. $n \bar{u}$ ), Tansel (turco tan "madrugada” + ár. sayl "torrente, inundação").

- turco e persa: Güllü (persa gol + sufixo turco -lü “indicador de posse"), Nazl1 (persa nāz "coqueteria, faceirice, garbosidade" + sufixo turco $-l I$ ), Candan "sincero, cordial" (persa djān "alma" + sufixo turco $-d A n)$.

\subsection{Antropônimos de origem turca no período pós-república}

Embora a diferença de porcentagem de nomes de origem turca ainda seja significativa em relação aos de origem árabe, ou seja, aproximadamente 30\%, 0 repertório do primeiro grupo teve um impressionante aumento de 18\% (14,8\% do total de 1.178 dos nomes no estudo de Duman), embora instável, num período de pouco mais de cem anos, de 1900 aos dias de hoje, constituindo o segundo lugar em número de nomes, atrás somente dos de procedência árabe.

É importante frisar com respeito aos nomes de origem turca que é comum que se adotem nomes escolhidos de lexemas comuns da língua moderna, o que possibilita um amplo leque de escolhas para os que não se contentam com os antropônimos já existentes, como o recente Gölge "sombra", que foi registrado somente após 2004 no estudo de Duman. Porém, a escolha, segundo essa autora, é baseada em razões estritamente estéticas, ou seja, são selecionadas somente palavras cujos significados são positivos ou foneticamente agradáveis,

15 Sem mencionar outros cujos étimos são desconhecidos: Zeyneti, Ziilbiye. 
aquelas que são eufônicas aos falantes. Além disso, o fato mais notável com respeito aos antropônimos turcos foi o abandono de vários nomes correntes na época da Turquia Otomana e a consequente adoção de nomes genuinamente turcos, alguns inclusive baseados nos neologismos criados pela Academia Turca de Letras (Türk Dil Kurumu), como é o caso de: Evrensu (< turco evren "universo"16 + su "água"), Coşku" "entusiasmo". Como se verá adiante, alguns nomes, à semelhança de palavras sugeridas para o léxico comum do turco pela Academia Turca de Letras, foram reavivados do turco antigo.

Abaixo segue uma classificação por campo semântico de prenomes e sobrenomes usados na Turquia moderna:

a) Ocupações: Assim como prenomes, os sobrenomes dessa categoria foram escolhidos em sua grande parte pela população rural: Demirci "Ferreiro", Arabacı "carroceiro", Çiftçi "fazendeiro", Bakırcı "caldeireiro em cobre", Halıci "tapeceiro", entre outros. Uma extensão dessa categoria é vista na adoção de patronímicos após as ocupações, como em Sarraçoğlu "filho do seleiro", Müftüoğlu "filho do mufti", na qual se obsẹrva o uso da palavra oğlu "filho de" (de oğul "filho");

b) Sobrenomes derivados de topônimos: usa-se em turco o sufixo -li, que ocorre em três versões mais de acordo com a natureza da vogal em que a última sílaba da palavra termina (harmonia vocálica) em quaisquer gentílicos. Alguns exemplos de sobrenomes com gentílicos, que foram adotados por grande parte da população, são: Konyalı "de Konya", Ankaralı "de Ancara”, Kayserili “de Kayseri”. De semelhante modo, houve a criação baseada em elementos da natureza, provavelmente característicos da região de onde provinha a pessoa: Denizli

16 Um neologismo datado de 1935. A partir do século XIV há a atestação de "dragão, serpente grande" no turco para essa palavra (Cf. LEWIS, 1999, p. 116; NIŞANYAN, 2003, p. 122). Num aparente lapso por parte dos puristas da Academia Turca de Letras, esta palavra foi julgada como sendo genuinamente turca, quando, na verdade, provém do verbo persa djōšídan "ferver". Note-se que tal raiz foi bastante produtiva na criação lexical no turco, produzindo uma gama de derivados: coşkulanmak, coşkulu, coşkun, coşkunluk, coşkusal, coşturmak, coşturucu, coşturuculuk, coşturulmak, coşu, coşumcu, coşumculuk e coşuntu (Cf. NIŞANYAN, 2003, p. 70). 
"costeiro" (< deniz), Dağli"montanhês" (< dăg), Köylü“aldeão"(< köy). É interessante notar que algumas dessas palavras também são usadas sem o sufixo - li, como Deniz, Dağ, além de nomes de regiões, como Ege "Egeu", ou nomes de rios, Menderes, Seyhan, Orhon (situado na Mongólia), Çoruh;

c) Epônimos tribais ou de heróis da história turca: como assinalado acima, houve uma crescente onda de adoção de nomes genuinamente turcos após o advento da república, com a política de Atatürk de "a Turquia para os turcos". Com isso, tornaram-se bastante comuns nomes que remetem a uma lealdade patriótica, como Selçuk "seljúcida", Gökalp, ${ }^{18}$ ou alguns baseados em antigos canatos da Ásia Central, cuja característica é o elemento -han (do turco antigo $x \bar{a} n$ ), como em Karahan, Ayhan, embora haja vários nomes compostos com - han que não possuem motivação histórica alguma: Altınhan, Akhan, Atahan, Balhan, Ayhan, ou nomes de heróis do período otomano, como Beyazıt, ou anteriores ainda, do período em que várias tribos turcas ainda viviam em regiões da Ásia Central: Oğuz, Kurultay, Ozansoy.

d) Elementos encontrados na natureza: além dos nomes que indicam um acidente geográfico típico da região da qual a pessoa provém, como já aludido acima, há a categoria de nomes que não têm nenhuma relação com elementos característicos, tais como Çakmak "pederneira", Duman "fumaça", Demirtaş "pedra de ferro", embora os dois primeiros elementos sejam remanescentes do passado nômade das tribos turcas ou de práticas xamanistas de tais tribos. $S u$ “água” é bastante comum em compostos: Akansu, Aksu, Çetinsu, Durgunsu, Arısu, Alsu, Akarsu, Berksu, Bensu, Çeliksu;

e) Partes do corpo: Baş "cabeça" com diversas combinações, como Akbaş, Altınbaş (ou na variante Altunbaş), Başçık, Başay, Baştaş, Baştemir; El "mão" com várias combinações, como Akel, Arıel, Canel, Açıkel, Aydınel;

18 Lit. "herói do céu" ou "herói azul". Ele é baseado no pseudônimo do famoso sociólogo, escritor e poeta turco Mehmet Ziya (1876-1924). 
Kol "braço", e suas combinações como Erkol, Arıkol, Çelikkol, Demirkol, Tunçkol, Mertkol; Göz "olho", como em Tepegöz (Olho no topo),19 Alagöz, Karagöz, ${ }^{20}$ Tokgöz, Gözaydın;

f) Animais: esta categoria é justificada pela prática do totemismo praticada entre os turcos pré-islâmicos. No épico turco O livro de Dede Korkut, há menção de várias personagens que afirmam ter parentesco com animais (Kazan, por exemplo, é chamado de "leão do rio Amıt, tigre dos Karadjuk"). Dentre uma gama de nomes, encontram-se A(r)slan "leão", Doğan e seus diversos compostos, e até outros menos nobres do ponto de vista islâmico, como Köpek "cachorro", e outros aparentemente pejorativos como Keçi "bode", Koyun "carneiro", Deve "camelo", Karga "corvo", Eşek"asno"; 21

g) Nomes eufônicos: por vezes, os falantes preferem deixar de conceder um conceito significativo para escolher palavras que soam eufônicas aos ouvidos dessa comunidade linguística, como: Akyavaş (ak "branco" + yavaş "devagar"), Ayben (ay "lua; mês" + ben "eu").

\section{Conclusão}

Apesar de nem o árabe nem o persa servirem de fontes de criação lexical no turco moderno, o mesmo não se pode dizer a respeito do repertório antroponímico turco, que é até, pode-se afirmar, criativo na produção de nomes próprios híbridos. A frequência de ocorrência dos nomes evidenciada na tabela elaborada por Duman revelou que, de fato, a secularização acompanhou a prática de nomear, sem que tenha havido, contudo, um rompimento total com

19 Este nome é uma referência ao personagem do épico turco Dede Korkut, nome que significa "Olho na testa", pois se tratava de um gigante com essa característica física.

20 Nome do personagem principal do teatro de sombras tradicional turco, que se tornou bastante popular durante o Império Otomano.

21 SPENCER, 1961, p. 215. Contudo, dessa lista, somente o derivado Karakoytun "Carneiro negro" (uma referência a uma federação tribal turca que governou entre os sécúlos XIV-XV) foi encontrado na extensa lista de prenomes e sobrenomes no site da Tïrk 1)il Kurumu (Academia Turca de Letras): <www.tdk.gov.tr>. 
o passado islâmico do período pré-república, fato esse que pode ser explicado, de uma maneira concisa e clara, pelas palavras do orientalista Bernard Lewis, que afirma que o "secularismo, tal como foi interpretado na República da Turquia, não significou o abandono, muito menos a supressão, da sua fé ancestral. De fato, ele significou uma clara separação entre religião e política [...] e uma mudança de identidade primária de comunidade e religião a país e nação" (LEWIS, 1998, p. 134).

\section{Referências bibliográficas}

BULLIET, R. W. "First names and political change in modern Turkey". In: International Journal of Middle Eastern Studies, 9/4. Nov., 1978, p. 489-5.

CRYSTAL, D. The Cambridge encyclopedia of language. $2^{\text {nd }}$ ed. Cambridge: Cambridge University Press, 1997.

DUMAN, D. "A characterization of Turkish personal name inventory”. In: International Journal of the Sociology of Language, 165, 2004, p. 155-77.

FINDLEY, C. V. The Turks in world history. New York: Oxford University Press, 2005.

HEYD, U. Language reform in modern Turkey. Jerusalem: The Israel Oriental Society, 1954.

LEWIS, B. The multiple identities of the Middle East. New York: Schocken, 1998.

LEWIS, G. The Turkish language reform: a catastrophic success. Oxford: Oxford University Press, 1999.

Turkey. London: Ernest Benn, 1955.

Turkish grammar. Oxford: Oxford University Press, 1967.

NIŞANYAN, S. Sözleri Soyağacı: çağdaş Türkçenin Etimolojik Sözlüğü. 2. ed. İstanbul: Adam, 2003.

SPENCER, R. F. "The social context of modern Turkish names". In: Southwestern Journal of Anthropology, v. 12, n. 3, 1961, p. 205-18.

TIETZE, A. Tarihi ve etimolojik Türkiye Türkçesi lugatı (Sprachgeschichtliches und etymologisches Wörterbuch des Türkei-Türkischen), cilt 1 A-E, İstanbul-Wien: Simurg/ Österreichische Akademie der Wissenschaften, 2002. 